\title{
Levedad, rapidez, consistencia: vida y literatura en Italo Calvino
}

\author{
Germán Bula
}

Universidad de la Salle, Bogotá, Colombia. Email: germanbula@yahoo.com

\begin{abstract}
Resumen: El presente escrito analiza tres de los valores literarios propuestos por Calvino en sus Seis propuestas para el próximo milenio, contemplando sus relaciones mutuas: levedad, rapidez y consistencia. Este último valor no pudo ser expuesto por Calvino, quien murió antes de terminar el libro. Por ello se intenta una reconstrucción a partir del material de la obra literaria de Calvino (concretamente, El Barón Rampante) y de lo dicho en las conferencias anteriores. El trabajo de relacionar los tres valores mencionados entre sí y de dar cuerpo al valor de la consistencia revela ciertas relaciones interesantes entre la vida biológica y la literatura en cuanto es de su esencia el tener un cierto conatus (en el sentido espinozista), una cierta organización que se esfuerza por perseverar en el ser.
\end{abstract} consistencia.

Palabras clave: Calvino, literatura, Spinoza, conatus, autopoiesis, Melville,

\section{Lightness, rapidity, consistency: life and literature in Italo Calvino}

\begin{abstract}
This paper analyzes three of the literary values given by Calvin in his Six propositions for the next millennium, contemplating their mutual relations: lightness, rapidity and consistency. The latter value could not be exposed by Calvin, who died before ending the book. Therefore a reconstruction is attempted from the material of Calvino's literary work (specifically, Baron Rampant) and what was said in previous conferences. The work of relating the three mentioned values to each other and to embody the value of consistency reveals some interesting relationships between biological life and literature as its essence is having a certain conatus (in the Spinozist sense), a certain organization that strives to persevere in being.
\end{abstract} consistency.

Key words: Calvino, literature, Spinoza, conatus, autopoiesis, Melville,

\section{Leveza, rapidez, consistência: a vida ea literatura Italo Calvino}

Resumo: O presente texto analisa três dos valores literários sugeridos por Calvino em suas Seis propostas para o próximo milênio contemplando suas relações mútuas: leveza, velocidade e consistência. Este último valor não pode ser exposto por Calvino, que morreu antes de terminar o livro. Por isso, tenta-se uma reconstrução a partir do material literário da obra de Calvino (especificamente El Barón Rampante) e do por ele dito nas conferências anteriores. O trabalho de relacionar os três valores indicados uns aos outros e de dar corpo ao valor da 
consistência, revela algumas relações interessantes entre a vida biológica ea literatura enquanto faz parte da sua essência ter um certo conatus (no sentido espinozista), uma organização que se esforça para perseverar no ser. consistência.

Palavras-chave: Calvino, literatura, Spinoza, conatus, autopoiese, Melville,

\section{The Unending Gift}

Un pintor nos prometió un cuadro. Ahora, en New England, sé que ha muerto. Sentí, como otras veces, la tristeza y la sorpresa de comprender que somos como un sueño. Pensé en el hombre y en el cuadro perdidos.

(Solo los dioses pueden prometer, porque son inmortales)

Pensé en un lugar prefijado que la tela no ocupará. Pensé después: si estuviera ahí, con el tiempo sería esa cosa más, una cosa, una de las vanidades o hábitos de mi casa; ahora es ilimitada, incesante, capaz de cualquier forma y cualquier color y no atada a ninguno. Existe de algún modo. Vivirá y crecerá como una música, y estará conmigo hasta el fin.

Gracias, Jorge Larco.

(También los hombres pueden prometer, porque en la promesa hay algo

inmortal)

Jorge Luis Borges

\section{Levedad, Rapidez, Consistencia}

El último escrito de Italo Calvino se llama Seis Propuestas para el Próximo Milenio, una serie de lecturas que planeaba leer en la universidad de Harvard. Murió una semana antes de las mismas y sin terminar la sexta conferencia, el 19 de septiembre de 1985.

En sus Seis Propuestas, Calvino explica los valores literarios que le son más caros, e invita a futuros escritores a utilizarlos. Es posible ver este último escrito de Calvino como un testamento, palabra que la Real Academia de la Lengua define así, "Obra en que un autor, en el último período de su actividad, deja expresados los puntos de vista fundamentales de su pensamiento o las principales características de su arte, en forma que él o la posteridad consideran definitiva.” En efecto, vistos desde su último escrito, los relatos de Calvino muestran un claro y resoluto esfuerzo por ceñirse a los seis valores que propone también para el futuro. ¿'Seis? Calvino com- 
pletó cinco de las conferencias que planeaba leer, con los títulos de Levedad, Rapidez, Exactitud, Visibilidad y Multiplicidad; de la última conferencia sólo se sabe el título, Consistencia, y que iba a tener que ver con Bartleby, el relato de Hermann Melville. El hecho de que Calvino no haya escrito esta última conferencia no quiere decir que el valor que en ella quería exaltar no esté presente en su obra, ni que nosotros no podamos imaginar los contenidos de su sexta conferencia. Es una suerte de unendinggift, de regalo sin fin.

A continuación hablaremos de tres de los valores que Calvino ha querido exaltar; Levedad, Rapidez y Consistencia. Partiendo de estos tres valores, pretendemos hacer una reflexión acerca de la naturaleza de la creación literaria, y de su relación con la vida, en sentido biológico.

En su primera conferencia, Calvino presenta la creación literaria como una lucha contra la pesadez:

En los momentos en que el reino de lo humano me parece condenado a la pesadez, pienso que debería volar como Perseo a otro espacio. No hablo de fugas al sueño o a lo irracional. Quiero decir que he de cambiar mi enfoque, he de mirar el mundo con otra óptica, otra lógica, otros métodos de conocimiento y verificación. Las imágenes de levedad que busco no deben dejarse disolver como sueños por la realidad presente y del futuro... (Calvino, 1989, 19)

La mirada literaria (que es necesariamente mirada sobre lo cotidiano, que es lo único que tenemos) es capaz de elevarse sobre la pesadez de lo cotidiano, sobre las restricciones y el sufrimiento, sobre la banalidad y la repetición. El relato de Borges que citamos arriba toma una situación perfectamente trivial, la muerte de un amigo, y despega. En pocas líneas se eleva hasta reflexionar sobre la condición humana y la naturaleza del prometer. Esta mirada, desde arriba, es capaz de ver claramente la pesadez de lo cotidiano (las vanidades o hábitos de la casa, lo trivial de las cosas con las que convivimos) porque ha alcanzado un punto de vista más ligero, porque ha tomado distancia del piso, de las infinitas exigencias de cargar con nuestra vida todos los días. Más adelante hablaremos de El Barón Rampante, relato de Italo Calvino acerca de un Barón del siglo dieciocho que pasa toda su vida en los árboles porque "quien quiere mirar bien la tierra debe mantenerse a la distancia necesaria” (Calvino, 2002, 178)

Para ilustrar este valor, Calvino cita un relato de Kafka, de 1917, cuyo "punto de partida es evidentemente una situación muy real de aquel invierno de guerra, el más terrible para el Imperio Austriaco: la falta de carbón” (Calvino, 1989, 40). En lugar de seguir la curva manida y predecible de la cotidianidad (salir a comprar o a mendigar carbón, no conseguirlo), la ficción sale disparada por una tangente:

Todo el carbón se había consumido; vacío el cubo; la pala, sin objeto ya; la chimenea respirando frío; el cuarto lleno de soplo de la helada 
(...) Necesito carbón; no debo congelarme; detrás de mí la chimenea inhospitalaria, ante mí, el cielo igualmente despiadado: deberé cabalgar entre ambos y en medio de ambos pedir ayuda al carbonero. Pero ante mis súplicas habituales él se ha endurecido ya (...) Debo actuar como el mendigo hambriento que decide expirar en el umbral de la puerta y a quien, por eso, la cocinera de los señores se decide a dar el poso del último café; así también (...) el carbonero tendrá que echarme una palada en el cubo.

Mi ascensión lo va a decidir; por eso voy hacia allí montado en el cubo. Jinete del cubo, y puesta la mano en el asa, riendas harto sencillas, desciendo penosamente la escalera; pero una vez abajo, mi cubo asciende; ¡magnífico!, ¡magnífico!; los camellos echados en tierra no se levantan sacudiéndose con más belleza bajo el palo del guía. Marchamos al trote por la callejuela helada; con frecuencia me veo alzado hasta el primer piso; nunca llego a descender hasta la puerta de la calle. Ante el abovedado sótano del carbonero floto a extraordinaria altura, en tanto él, allá abajo, escribe, encogido ante su mesita; para dar paso al calor excesivo ha abierto la puerta.

— ¡Carbonero! — gritó, con voz hueca, quemada por el frío y oculto por las nubes de mi aliento lleno de humo-, por favor, carbonero, dame un poco de carbón. Mi cubo está vacío, ya no puedo cabalgar sobre él. Sé bueno. Tan pronto pueda, te pagaré.

El carbonero se lleva la mano al oído.

(...)

-Mujer — dice el carbonero-, ahí hay alguien, hay alguien; no puedo equivocarme hasta ese extremo; tiene que ser un cliente antiguo, muy antiguo, para que así me hable al corazón.

—_Qué te pasa hombre? — dice la mujer, y aprieta su labor contra el pecho, descansando por un instante-. No hay nadie, la calle está vacía y toda nuestra clientela está ya servida; podemos cerrar el negocio por unos días y descansar.

-Pero yo estoy aquí, sobre el cubo — gritó, e insensibles lágrimas de frío velan mis ojos_- Por favor, aquí arriba; me veréis en seguida; tan sólo una palada; y si me dierais dos, me haríais más que feliz. (...) —Voy —dice el carbonero, y quiere subir la escalera con sus cortas piernas, pero la mujer está ya junto a él, le coge por el brazo y dice: - Tú te quedas. Si no desistes de tu testarudez, seré yo quien suba. Acuérdate de tu tos.

(...)

-Señora carbonera —exclamo_- la saludo; sólo una palada de carbón; aquí, en seguida, en el cubo; yo mismo lo llevaré a casa; una palada del peor. La pagaré toda, claro está, pero no ahora, no ahora. ¡Qué tañido de campanas son esas dos palabras, "no ahora", y qué turbadora para los sentidos que se mezclan al toque del reloj que precisamente me llega desde la cercana torre de la iglesia!

-¿Qué es, pues, lo que quiere? -exclama el carbonero,

—Nada - le replica la mujer- no hay nadie; no veo nada, no oigo nada; sólo están dando las seis y nosotros cerramos. Hace un frío terrible; es probable que mañana tengamos mucho trabajo aún. 
No ve nada, no oye nada, y sin embargo, suelta la cinta de su delantal y procura alejarme con él. Por desgracia lo consigue. Mi cubo tiene todas las desventajas de un animal de silla; carece de fuerzas para resistir; es demasiado liviano; un delantal de mujer obliga a sus patas a dejar el suelo.

— ¡Mala mujer! — grito aún, mientras ella, volviéndose hacia el negocio, entre despreciativa y satisfecha, hace un gesto en el aire con la mano-. ¡Mala! Te pedí una palada del peor y no me la has dado. Y con ello me elevo a las regiones de los pinos helados y me pierdo de vista para siempre. (Kafka, 1999).

Es importante hacer notar que el relato no es escapista, al contrario agudiza la crudeza de una situación real. Dicho de otro modo, es porque el cubo está vacío que se puede elevar, primero unos pocos metros por encima de la calle y después hasta el infinito.

Leve es el vuelo del Quijote por los aires tras atacar a los molinos de viento, leves los pies de Perseo, y la rana de Basho que salta al estanque. Leve es el instrumento de Sherezade, el relato, contra el pesado poder y el pesado rencor del sultán Shariahr en Las Mil y Una Noches.

¿Cómo, pues, desprenderse del piso, hacerse ligero, volar? Las naves espaciales alcanzan la ingravidez del espacio gracias a lo que se llama "velocidad de escape", con la que se supera la fuerza gravitatoria de la tierra. La rapidez será también un valor de la literatura, y para propósitos análogos. Calvino cita la siguiente reflexión de Leopardi: "La velocidad, por ejemplo de los caballos, ya sea vista, ya experimentada (...) es gratísima en sí misma por la vivacidad, la energía, la fuerza, la vida de esa sensación. Despierta realmente una casi idea de infinito, eleva el alma, la fortalece" (Leopardi, citado en Calvino, 1989, 55).

No hablamos de la rapidez del afán o del descuido, sino la rapidez del “apurémonos despacio”, la rapidez ágil y precisa. Esta rapidez queda ilustrada, tanto por la forma como por el contenido, en este relato oriental vuelto a contar por Italo Calvino:

Entre sus muchas virtudes, ChuangTzu tenía la de ser diestro en el dibujo. El rey le pidió que dibujara un cangrejo. ChuangTzu respondió que necesitaba cinco años y una casa con doce servidores. Pasaron cinco años y el dibujo aún no estaba empezado. "Necesito otros cinco años” dijo ChuangTzu. El rey se los concedió. Transcurridos los diez años, ChuangTzu tomó el pincel y en un instante, con un solo gesto, dibujó un cangrejo, el cangrejo más perfecto que jamás se haya visto. (Calvino, 1989, 67).

La rapidez consiste en la capacidad de hacer estallar de sentido unas pocas líneas, de pasar en un solo y fluido movimiento del piso y de lo trivial a la región de lo ligero. Veamos este microcuento de Jorge Campo, Travesura: 
Escondido en el callejón, saca del bolsillo una piedra y su cauchera. Con ritual estratégico coloca una dentro de la otra. Dejándola lista para disparar.

Mira a la derecha, mira a la izquierda, hacia arriba y zuás. Minutos después llora en la falda de su madre porque el cielo se cae a pedazos. (Citado en Rodríguez Romero, 1996)

\section{Manzanas:}

Y este otro, de Ana María Shua titulado De la Ubicuidad de las

La flecha disparada por la ballesta precisa de Guillermo Tell parte en dos la manzana que está a punto de caer sobre la cabeza de Newton. Eva toma una mitad y le ofrece la otra a su consorte para regocijo de la serpiente. Es así como nunca llega a formularse la ley de gravedad. (Citado en Rodríguez Romero, 1996)

En este último relato, un evento se sigue al otro según una cierta norma interna que rige los movimientos, el paso de un evento al siguiente. Gracias a la velocidad, la norma se cristaliza y se transparenta. El goce del relato yace en su velocidad. Calvino cita una vieja leyenda para ilustrar este punto, anotando que sólo funciona si es narrada con la debida rapidez:

El emperador Carlomagno se enamoró, siendo ya viejo, de una muchacha alemana. Los nobles de la corte estaban muy preocupados porque el soberano, poseído de ardor amoroso y olvidado de la dignidad real, descuidaba los asuntos del Imperio. Cuando la muchacha murió repentinamente, los dignatarios respiraron aliviados, pero por poco tiempo, porque el amor de Carlomagno no había muerto con ella. El Emperador, que había hecho llevar a su aposento el cadáver embalsamado, no quería separarse de él. El arzobispo Turpín, asustado de esta macabra pasión, sospechó un encantamiento y quiso examinar el cadáver. Escondido debajo de la lengua muerta encontró un anillo con una piedra preciosa. No bien el anillo estuvo en manos de Turpín, Carlomagno se apresuró a dar sepultura al cadáver y volcó su amor en la persona del arzobispo. Para escapar de la embarazosa situación, Turpín arrojó el anillo al lago de Constanza. Carlomagno se enamoró del lago de Constanza y no quiso alejarse nunca de sus orillas. (Calvino, 1989, 45).

El relato es guiado de un evento al siguiente por una regla que lo ordena (el poder mágico del anillo); si se contara en mayor detalle, con mayor parsimonia, la regla se perdería en los detalles, y se perdería también el gozo de la velocidad, del paso de un evento al siguiente.

Lo que permite al relato desprenderse del mundo y cobrar vida propia es una determinada regla de movimiento, y la vida del relato consiste en su adhesión a dicha regla. Si el anillo perdiera sus poderes, todo el asunto no sería más que un breve episodio de locura por parte de Carlomagno, nada especialmente digno de contarse. Apenas Don Quijote deja de ver el 
mundo según el lenguaje de los libros de caballería (convirtiendo a las rameras en doncellas, a los rebaños en ejércitos y a los molinos en gigantes), muere, y con él muere el relato. Sherezade debe ensartar un relato dentro de otro, y otro dentro de otro, con la certeza de que terminar el relato significaría su propia muerte.

Y he aquí el último valor que quiso exaltar Calvino, cuya conferencia se quedó en meros apuntes preparatorios, la consistencia. La vida de un relato yace en su ceñirse a unas determinadas leyes internas, que son como el alma del relato. La consistencia es la capacidad de un relato de perseverar en su ser, de seguir sus propias leyes aun cuando su consistencia se ve amenazada. Decimos de los relatos lo mismo que dice Spinoza, en su famosa doctrina del conatus, acerca de los 'modos' o cosas finitas, que cada una "se esfuerza en cuanto está a su alcance por perseverar en su ser" (1999, Proposición 7, Libro Tercero).

Este último punto lo ilustraremos con Bartleby, de Hermann Melville, un texto al que Calvino pretendía aludir en su última conferencia. Bartleby, un escribiente de figura "pálidamente pulcra, lamentablemente respetable, incurablemente solitaria" entra a trabajar a la oficina de un abogado de Wall Street, Es un eficiente copista, y trabaja con constancia y empeño. Un día, su empleador le pide que revise unos documentos con él, a lo que Bartleby responde así: "Preferiría no hacerlo". Así reacciona el abogado, que es el narrador de la historia:

Me quedé un rato en silencio perfecto, ordenando mis atónitas facultades. Primero, se me ocurrió que mis oídos me engañaban o que Bartleby no había entendido mis palabras. Repetí la orden con la mayor claridad posible; pero con claridad se repitió la respuesta:

-Preferiría no hacerlo.

-Preferiría no hacerlo -repetí como un eco, poniéndome de pie, excitadísimo y cruzando el cuarto a grandes pasos-. ¿Qué quiere decir con eso? Está loco. Necesito que me ayude a confrontar esta página: tómela -y se la alcancé.

-Preferiría no hacerlo -dijo. (Melville, 1979)

Vencido, el empleador llama a otro de sus asistentes para revisar el escrito. Bartleby continúa haciendo su trabajo como copista. Consistentemente se niega a cualquier trabajo que no sea el de copiar escritos legales, siempre con la misma frase "Preferiría no hacerlo". Su empleador, desesperado, le pregunta a Bartleby por qué se niega a hacer su trabajo, a lo que este responde, sereno e impasible "preferiría no hacerlo". La constancia de Bartleby restaura transitoriamente el equilibrio en la oficina. Nos dice el narrador:

Con el tiempo, me sentí considerablemente reconciliado con Bartleby. Su aplicación, su falta de vicios, (...) su ecuánime conducta en todo momento, hacían de él una valiosa adquisición. En primer lugar siempre estaba ahí, el primero por la mañana, durante todo el día, y el 
último por la noche. (...) Sentía que mis documentos más importantes estaban perfectamente seguros en sus manos. A veces (...) no podía evitar el caer en espasmódicas cóleras contra él. Pues era muy difícil no olvidar nunca esas raras peculiaridades, privilegios y excepciones inauditas, que formaban las tácitas condiciones bajo las cuales Bartleby seguía en la oficina. A veces, en la ansiedad de despachar asuntos urgentes, distraídamente pedía a Bartleby, en breve y rápido tono, poner el dedo, digamos, en el nudo incipiente de un cordón colorado con el que estaba atando unos papeles. Detrás del biombo resonaba la consabida respuesta: preferiría no hacerlo; y entonces ¿cómo era posible que un ser humano dotado de las fallas comunes de nuestra naturaleza dejara de contestar con amargura a una perversidad semejante, a semejante sinrazón? Sin embargo, cada nueva repulsa de esta clase tendía a disminuir las probabilidades de que yo repitiera la distracción. (Melville, 1979)

Un domingo, el narrador encuentra a Bartleby en su oficina, y descubre que ha estado viviendo allí, que nunca sale de la oficina. Estupefacto, el empleador quiere averiguar sobre Bartleby:

Bartleby -dije en tono aún más suave- venga, no le voy a pedir que haga nada que usted preferiría no hacer. Sólo quiero conversar con usted.

Con esto, se me acercó silenciosamente.

-¿Quiere decirme, Bartleby, dónde ha nacido?

-Preferiría no hacerlo.

-¿Quiere contarme algo de usted?

-Preferiría no hacerlo.

-Pero ¿qué objeción razonable puede tener para no hablar conmigo? Yo quisiera ser un amigo.

Mientras yo hablaba, no me miró. Tenía los ojos fijos en el busto de Cicerón, que estaba justo detrás de mí, a unas seis pulgadas sobre mi cabeza.

-¿Cuál es su respuesta, Bartleby? -le pregunté, después de esperar un buen rato, durante el cual su actitud era estática, notándose apenas un levísimo temblor en sus labios descoloridos.

-Por ahora prefiero no contestar -dijo, y se retiró a su ermita. (Melville, 1979)

Después de este episodio, Bartleby deja de trabajar, por lo que es despedido. Sin embargo, cuando se le pide que deje el edificio, responde con su consabida frase. El abogado termina por decidir trasladar su negocio, dejando atrás a Bartleby en una oficina vacía. Los nuevos ocupantes del edificio se quejan de la presencia de Bartleby, que es llevado a la cárcel, donde muere tras rehusarse a recibir alimentos.

El conjuro que convierte a este relato en literatura es la consistencia de Bartleby, consistencia que persevera siempre que se ve amenazada. Si en algún momento Bartleby abandonara su regla de acción, el relato como tal 
se vendría abajo. Podría argumentarse que la persistencia de Bartleby lo lleva a la muerte, pero sin ella no sería Bartleby, aún si viviera. Bartleby, copista, debe permanecer fiel al original.

La literatura es un grácil movimiento vertical, un elevarse, como el barón de Münchhausen, tirando de los cordones de las propias botas; un esfuerzo guiado por normas internas para alcanzar la velocidad de escape y vencer la gravedad, la pesadez de la tierra. Este esfuerzo requiere que la literatura se afirme a sí misma, que no abandone las reglas que ha creado para sí, distintas de las de la cotidianidad.

\section{El Barón Rampante}

A los doce años, Cosimo Piovasco di Rondo, habitante de Ombrosa, en Génova, se subió a un árbol tras una pelea con sus padres, que querían hacerle comer caracoles, y juró no volver a bajar nunca, sino vivir de árbol en árbol. La pataleta infantil se convierte en una opción de vida; Cosimo vive, ama y lucha, sin jamás bajarse de los árboles; en los árboles es pareja de Viola; desde los árboles tiene correspondencia con Diderot, y escribe tratados ilustrados; desde los árboles conversa con Napoleón. Jamás toca el piso de nuevo, y al momento de morir se cuelga de un globo que va pasando, y cuando éste aterriza, no se ve siquiera un rastro del Barón de Rondó, como cuenta Biagio, su hermano menor, el narrador de la historia. Esta es la trama de El Barón Rampante de Italo Calvino, que nos servirá para mostrar el conatus que tienen las obras literarias.

La decisión de Cosimo de subir a los árboles proviene de una pataleta infantil, “...j Ya verás en cuanto bajes!” dice el padre, “¡No bajaré nunca!” replica el hijo (Calvino, 2002, 27). ¿La causa? El hijo se rehúsa a comer caracoles (imagen de lentitud, y de unión al suelo). Terco y comprometido, Cosimo se apega a su decisión de quedarse en los árboles y, andando de rama en rama, llega por primera vez al jardín de los Ondariva. Los Ondariva son los vecinos de al lado, pero un pesado muro y pesadas peleas entre dos familias nobles habían hasta ese momento evitado que Cosimo conociera el jardín de al lado; sólo el brinco entre los árboles supera la pesadez. Allí encuentra a una niña, Viola, que se balancea sobre un columpio colgado de una rama. Ésta deja caer una manzana, y el niño, fiel a su promesa, la recoge sin dejar la rama de magnolia sobre la que está, usando su espadín. Jactancioso, Cosimo relata a Viola su decisión de vivir en los árboles y ésta le propone ciertas reglas:

- (...)Tu tienes el dominio de los árboles, ¿vale? Pero si tocas una vez tierra con un pie, pierdes todo tu reino y te vuelves el último de los esclavos. ¿Entendido? Incluso si se te rompe una rama y caes, ¡todo perdido!

- ¡Jamás me he caído de un árbol en mi vida!

- Bueno, pero si caes, si caes te conviertes en cenizas y el viento te arrastra. 
Normalmente, un contrato así terminaría olvidado, anulado por la pesadez de la vida: hay que bajar a comer, o por el frío, o por todos los procesos entrópicos que se enfrentan mejor desde la tierra. Pero no es tan rígido el contrato como para que forzosamente se quiebre: como mostrará el relato, Cosimo puede vivir, estudiar, amar, luchar en las guerras napoleónicas sin bajar de los árboles (a diferencia de ahora, en el tiempo del relato hay suficientes bosques como para que sea posible viajar largas distancias de árbol en árbol). Un contrato no es como una viga, sino como una cuerda. Dice Michel Serres en El Contrato Natural:

La cuerda sirve para tirar. Tirar, apretar, eso en definitiva equivale a un brazo, que puede unir, y a una mano, que sabe asir. En ausencia del órgano, el lazo continua siendo eficaz, y funciona solo.

Por su flexibilidad, que permite al que ella ata grados de libertad, la cuerda, sin embargo, triunfa sobre el brazo o el palo, que sólo efectúan relaciones rígidas. Al igual que la cabra puede pastar la corona de hierba alrededor de la estaca, en la circunferencia descrita por su soga o ronzal, de igual modo, en un entorno próximo, va y viene aquel al que sólo la extrema tensión es capaz de bloquear.

El derecho marca límites. El lazo hace sensibles esos bordes, pero sólo cuando deviene derecho; con anterioridad define un espacio, plano o volumen, libre y sin lazo. O un área de no derecho en el interior del derecho (Serres, 2004, 174-175).

Puedo transitar libremente al interior de mi país; el derecho internacional sólo se hace sentir en las fronteras; como arrendatario, mi contrato me permite habitar un solar, ponerle los muebles que quiera, llegar a la hora que quiera, pero no, por ejemplo, hacer remodelaciones al apartamento. La libertad de mi perro se mide por el largo de su correa. La tensión del contrato, de la cuerda, sólo se siente en el límite, más allá del cual el contrato se rompe: "Así la variación que precede a la frontera es tan importante como el borde. Cuando la cuerda está tensa, rígida, imita al sólido; en reposo, flexible, enroscada, plegada, inmóvil, enrollada en cables, la cuerda se invagina, ausente” (Serres, 2004, 175).

El pacto que Cosimo hace consigo mismo le permite cierta libertad, es flexible; nada dice el pacto de no tener relaciones amorosas con mujeres (siempre que sea en los árboles), de no recibir ayuda médica en momentos de enfermedad (el médico ayudado por una escalera), de no leer, o hacer política o luchar con piratas. Esta libertad dentro del contrato permite que haya un relato como tal. Ahora bien, el pacto es inflexible en lo que respecta a tocar tierra. Sin la lucha por la existencia no se da la evolución, en ausencia de dificultades (así sean autoimpuestas), se da la creatividad. En esta tensión entre la regla interna del relato y situaciones que la amenazan, está la gracia y el sabor de la literatura:

Junto al columpio de Viola había otro, colgado de la misma rama (...) Cosimo se dejó caer desde la rama agarrado a una de la cuerdas (...) se puso de pie en el columpio y para darse impulso desplazó el peso del cuerpo 
doblándose por las rodillas y lanzándose hacia adelante (...)

- Si pruebas a sentarte y a darte impulso con los pies llegas más arriba- insinuó Viola.

Cosimo le hizo una mueca.

- Baja a empujarme, sé bueno- dijo ella, sonriéndole amable.

- $\quad$ No, yo, habíamos dicho que no debía bajar a ningún precio (...)

- Sé amable.

- No.

- ¡Ja, ja! Estabas a punto de picar. ¡Si ponías un pie en el suelo lo perdías ya todo!- Viola bajó del columpio y empezó a dar ligeros empujones al columpio de Cosimo-. ¡Huy!-había agarrado de repente el asiento del columpio donde (...) tenía los pies y le había dado la vuelta. ¡Por suerte Cosimo se sujetaba muy fuerte de las cuerdas (...) - ¡Traidora!- gritó y trepó hacia arriba, sujetándose de las dos cuerdas, pero la subida era mucho más difícil que la bajada, sobre todo con la niña rubia que estaba en uno de sus momentos malignos y tiraba desde abajo las cuerdas en todos los sentidos. (Calvino, 2002, 37).

Cosimo debe perseverar en su ser, como Bartleby debe perseverar en su ser, y el anillo mágico del relato de Carlomagno debe, no importa cómo cambie la situación, seguir operando su magia. Bartleby debe seguir en la oficina, con gentil y pasiva resistencia, aún si la oficina ya no está ahí. El anillo debe suscitar el amor de Carlomagno, aún si la muchacha que lo tiene haya muerto (necrofilia), o si pasa a manos del arzobispo (homosexualismo) o al fondo del lago de Constanza (topofilia). En cada giro, el relato tiene que arreglárselas para perseverar en su ser, a pesar de los cambios y exigencias del mismo relato. La tensión exige soluciones creativas. El arzobispo, al intentar deshacerse del conjuro del anillo, tan sólo consigue forzarlo a una solución poética: "Para escapar de la embarazosa situación, Turpín arrojó el anillo al lago de Constanza. Carlomagno se enamoró del lago de Constanza y no quiso alejarse nunca de sus orillas.” (Calvino, 1988, 45).

Estos relatos deben seguir la norma interna que para sí se han fijado; y el lector debe colegir la manera en que cada relato persevera en su ser. No corresponde al relato enunciar explícitamente su conatus, le corresponde vivirlo. Mostrar y no decir es regla fundamental de la literatura: si Melville hubiera enunciado, al comienzo o al final o en el medio del relato, el conatus que rige a Bartleby, hubiera destruido su relato. Si al contar la leyenda del anillo mágico dijéramos: "este relato trata de cómo un anillo mágico hace que Carlomagno se enamore de los diversos seres o cosas que lo tienen, sin importar si el amor es decoroso o usual” mataríamos el relato, más o menos de la forma en que explicar un chiste lo destruye.

En El Barón Rampante se dramatiza esta regla de la literatura, cuan- 
do, tras muchos días (todos en los árboles) y después de haberse asociado con una pandilla de ladrones de fruta, Cosimo vuelve a encontrar a Viola, que monta a caballo y mastica distraídamente la fusta. Por decir alguna cosa, frente a un encuentro inesperado, sólo atina a decir:

- ¿Sabes que nunca he bajado de los árboles desde entonces?

Las empresas que se basan en la tenacidad interior deben ser mudas y oscuras; a poco que uno las declare o se gloríe de ellas, todo parece fatuo, sin sentido, e incluso mezquino. Así, mi hermano, apenas pronunciadas esas palabras hubiera querido no haberlas dicho nunca, y ya no le importaba nada de nada, e incluso le entraron ganas de bajar y acabar de una vez. Tanto más cuanto que Viola se quitó lentamente la fusta de la boca y dijo, en tono amable:

- ¿Ah sí? ¡Menudo Gaznápiro!

De las bocas de aquellos piojosos [los ladrones de fruta] empezó a bramar una carcajada, antes aún de que se abrieran y estallaran en alaridos a más no poder, y Cosimo allá arriba en la higuera tuvo tal estremecimiento de rabia que la higuera, de madera traidora, no resistió; una rama se rompió bajo sus pies. Cosimo cayó como una piedra (Calvino, 2002, 62-63)

En este texto hacemos crítica literaria, no literatura. Por tanto, exentos de la regla de mostrar y no decir, explicitamos nuestra tesis: la regla interna del relato, su conatus, es la vida del relato; y a menudo, por ejemplo en el Quijote (que muere en cuanto se sana de su locura) o en el Barón Rampante, la vida del relato y la vida del protagonista están entrelazadas. El conatus del relato consiste en su hacerse efectivo, mostrarse, no en su explicitarse. La explicitación hace peligrar al relato. Dejamos a Cosimo en peligro de muerte, quizás biológica, sin duda literaria. Sólo lo salva un sutilísimo deus ex machina:

Se desplomó con los brazos abiertos, no se sostuvo. Fue la única vez, a decir verdad, durante su estancia en los árboles de esta tierra, que no tuvo voluntad ni instinto para agarrarse. Pero un borde del faldón del frac se enganchó en una rama baja; Cosimo se encontró colgado del aire a cuatro palmos del suelo, cabeza abajo (Calvino, 2002, 63).

Cosimo crece entre los árboles que, formando un tejido espeso con pocas discontinuidades, le permiten recorrer grandes distancias de su región. Merodea, y de noche se encuentra con que los piratas que hostigan los barcos de la región guardan su botín (bacalao seco, queso de cabra, etc.) en una cueva en la playa.. En lugar de avisar a los comerciantes para que recuperen sus mercancías, el noble de los árboles decide avisar a los pobres carboneros que viven en el bosque, que darán mejor uso del botín. Dirígense a la cueva, y al querer entrar descubren que está cuidada por varios piratas armados con cimitarras. Muere el centinela que da el aviso, "Cosimo estuvo en pocos saltos en una rama encima de él y le clavo la espada en los riñones (...)” (Calvino, 2002, 146). Sigue una batalla entre 
piratas y carboneros, en la que los primeros, más numerosos, comienzan a tomar ventaja, y los jefes comienzan su huída:

Por parte mahometana aún resistían bajo una granizada de piedras cuando vieron que el camino del mar estaba libre. ¿Resistían para qué, pues? Mejor izar velas e irse.

Alcanzada la navecilla, tres piratas, todos nobles oficiales, soltaron la vela. De un salto Cosimo se lanzó al mástil desde un pino próximo a la orilla; se agarró al durmiente de la verga y allí arriba, sujetándose con las rodillas, desenvainó la espada. Los tres piratas alzaron las cimitarras. (...) La barca, aún atracada, se inclinaba ora a un lado, ora a otro (...) [Cosimo] se deslizó hacia abajo por el palo y hundió la espada en el pecho de un pirata que cayó por la borda. Rápido como un lagarto, volvió a subir (...) luego volvió a dejarse caer y ensartó al segundo, volvió a subir, tuvo una breve escaramuza con el tercero y en otro de sus deslizamientos lo atravesó (Calvino, 2002, 147).

Así se da una batalla en un barco, entre piratas mahometanos y uno que ha jurado nunca bajarse de los árboles y, de alguna manera, lo cumple. La situación extrema tensa el lazo que une a Cosimo a los árboles; tensión de la batalla, tensión contractual, tensión creativa; si Cosimo se deja caer, muere; y si cae muere el relato.

La vida, biológica o literaria, es creativa; se multiplica y diversifica, por su propia dinámica interna. Los relatos reiterados de una experiencia se modifican solos; cada vez que se cuenta un relato de pesca, el pez crece unos cuantos centímetros. Las historias se mezclan entre sí, mutan, evolucionan, ganan caracteres. El Barón de Münchhausen (a quien Calvino cita como inspiración para El Barón Rampante, ver 2002, 10) personaje histórico, Barón del siglo XVII, luchó en varias campañas contra los turcos; los relatos de sus experiencias fueron creciendo hasta volverse un corpus de narraciones fantásticas a manos de R.E Raspe y otros autores. Lo allí relatado es vivo ejemplo de levedad y rapidez: acompañado de Berthold, su secuaz que es tan veloz que debe usar grilletes para caminar a velocidad normal, monta en una bala de cañón, baila en el estómago de una ballena y viaja a la luna. El relato, como el Barón en una de sus hazañas, se saca a sí mismo de una ciénaga tirando de los cordones de sus propias botas: a cada dificultad o contradicción que se le opone a un invento o fanfarronada, se opone un invento y una fanfarronada mayor: velocidad de escape, la vida engendrando vida y el relato, relato.

Cosimo, el Barón que nos ocupa, no está por encima del relato ampliado y la fanfarronada. Así presenta su hermano Biagio, el narrador, la anécdota de los piratas:

La historia que ahora referiré fue narrada por mi hermano en muchas versiones diferentes: me atendré a la más rica en detalles y menos ilógica. Aunque es muy cierto que mi hermano, al contar sus aventuras, les añadía mucho de su cosecha, yo, a falta de otras fuentes, 
intento siempre atenerme al pie de la letra de lo que decía. (Calvino, 2002, 142)

Cosimo cuenta sus historias en la plaza pública, con la jactancia y el recurso a la fantasía para salvar la fantasía que caracterizan al Barón de Münchhausen:

Por ejemplo, uno de aquellos desocupados le preguntaba:

- ¿Pero, es cierto que nunca habéis puesto el pie fuera de los árboles, señor Barón?

Y Cosimo empezaba:

- Sí, una vez, por equivocación subí a los cuernos de un ciervo. Creía pasar a un arce, y era un ciervo escapado del coto de caza real que estaba allí quieto. El ciervo siente mi peso en los cuernos y huye por el bosque. ¡Imaginaos qué trance! (...) El ciervo se debatía, tratando de librarse de mí, yo me sujetaba con fuerza...

(...)

- ¿Y cómo salistéis del paso, señoría?

$\mathrm{Y}$ el cada vez inventaba un final distinto:

- El ciervo corrió, corrió, se reunió con la tribu de los ciervos que al verlo con un hombre entre los cuernos en parte le escapaban y en parte se le acercaban curiosos. Yo apunté el fusil que llevaba siempre en la bandolera, y a cada ciervo que lo veía lo derribaba. Maté cincuenta...

- ¿Y desde cuando ha habido cincuenta ciervos por nuestras tierras?- le preguntaba alguno de aquellos belitres.

- Ahora se ha perdido la raza... Porque aquellos cincuenta eran todos ciervos hembras, ¿comprendéis? Cada vez que mi ciervo se acercaba a una hembra, yo disparaba y ella caía muerta. El ciervo no podía explicárselo, y estaba desesperado... Entonces..., entonces decidió matarse, corrió a una roca alta y se tiró desde allí. Pero yo me agarré a un pino que sobresalía, iy aquí estoy! (Calvino, 2002, 154155)

Ante la amenaza (¿cuándo ha habido cincuenta ciervos?), la fantasía recurre a la fantasía; el relato vive del relato y sólo vence la pesadez volando aún más alto. Más adelante, Cosimo ayudará a los habitantes de Ombrosa a combatir lobos bajados de los Alpes, colgando ovejas vivas de los árboles, como frutas, para atraerlos al bosque y ahí, disfrazado de oveja, dispararles. Cerca de cada oveja había oculto un fusil en un árbol. Así cuenta el Barón parte del combate:

- La batalla se desarrollaba de la mejor manera cuando, al avanzar hacia el árbol de la oveja, encontré tres lobos que habían conseguido trepar a las ramas y la estaban rematando (...) los lobos, al ver aquella otra oveja que caminaba en dos patas por las ramas se volvieron contra ella abriendo de par en par en las fauces todavía rojas de sangre. Yo tenía el fusil descargado, porque después de tantos disparos me había quedado sin pólvora; y el fusil preparado en aquel 
árbol no podía alcanzarlo porque estaban los lobos. Estaba sobre una rama secundaria y un poco tierna, pero encima tenía al alcance del brazo una rama más fuerte. Empecé a caminar hacia atrás por mi rama, alejándome lentamente del tronco. Un lobo, lentamente, me siguió. Pero yo con las manos me sujetaba a la rama de arriba, y fingía mover los pies sobre aquella rama tierna; en realidad me colgaba de arriba. El lobo, engañado, se fió al avanzar; y la rama se dobló bajo su peso, mientras yo de un salto me levantaba sobre la rama de encima. El lobo cayó con un ladrido de perro apenas insinuado, y en tierra se rompió los huesos quedándose tieso.

- ¿Y los otros dos lobos?

- ... Los otros dos me estaban estudiando, inmóviles. Entonces, de un solo golpe, me quité la casaca y la capucha de piel de oveja y se los arrojé. Uno de los lobos, al verse volar encima esta sombra blanca de cordero, trató de aferrarla con los dientes, pero al estar preparado para sostener un gran peso y encontrarse con un despojo vacío, se desequilibró y perdió pie, acabando también por romperse patas y cuello en el suelo.

- Aún queda uno...

- ... Aún queda uno, pero al haberme aligerado repentinamente de ropa cuando tiré la casaca, me acometió uno de esos estornudos que hacen temblar el cielo. Y al lobo, con aquel estruendo tan repentino y nuevo, le dio tal susto que cayó del árbol rompiéndose el cuello como los otros (Calvino, 2002, 221-222).

Nótese, primero, cómo caer coincide con morir a lo largo de toda la batalla; y, segundo, cómo es la ligereza lo que vence a los lobos: la ligereza para colgarse de una rama superior, la ligereza de la piel de cordero lanzada, el estornudo, una nada, un ruido, pero suficiente para acabar con los elementos pesados.

Un hombre sobre un árbol, separado varias yardas de la tierra, es un estado de cosas difícil de sostener. La ley de la gravedad conspira en su contra; también la ley de la entropía: los sistemas tienden hacia el equilibrio, inexorablemente, mientras que los árboles, y los Barones que en ellos habitan, son sistemas alejados del equilibrio gracias a un constante flujo de materia y energía. Dicho de otro modo, la muerte se opone a que Cosimo siga en los árboles. Como cadáver, o como viejo enfermo, ha de bajar, así sea para recibir tratamiento médico. Pues bien, los habitantes de Ombrosa le suben una cama y una butaca, y varios médicos suben y bajan por escaleras para darle atención en un nogal en la plaza. Pues bien:

Una mañana no lo vimos ni en la cama ni en la butaca, y alzamos la mirada, atemorizados: había subido a la cima del árbol y estaba a horcajadas de una rama altísima, con sólo una camisa encima.

- ¿Qué haces allá arriba?

No contestó, estaba semirrígido. Parecía mantenerse en la cima por milagro. Preparamos un gran lienzo, de esos de recoger aceitunas, y nos pusimos unas veinte personas a tenerlo extendido, porque se 
esperaba que cayese. (...)

Los hombres que sostenían el lienzo estaban cansados. Cosimo permanecía arriba sin moverse. Se levantó el viento, el lebeche, la cumbre del árbol ondeaba, nosotros estábamos preparados. Y en estas apareció en el cielo un mongolfier.

Ciertos aeronautas ingleses hacían experimentos de vuelo en mongolfier sobre la costa. Era un hermoso globo, adornado con flecos y franjas y borlas, con una barquilla de mimbre colgada (...)

$\mathrm{Y}$ he aquí que el mongolfier fue cogido por una racha de lebeche; empezó a correr con el viento girando como una peonza, e iba hacia el mar, Los aeronautas, sin perder la cabeza, se dedicaban a reducircreo- la presión del globo, y al mismo tiempo arrojaron el ancla para tratar de sujetarse en algún punto. El ancla volaba plateada en el cielo, colgada de una larga soga, y al seguir oblicuamente la carrera del globo pasaba ahora sobre la plaza, y estaba casi a la altura de la cima del nogal, hasta el punto que temimos que golpeara a Cosimo (...)

El agonizante Cosimo, en el momento en que la soga del ancla pasó a su lado, dio un salto de los que le eran habituales en su juventud, se agarró a la cuerda, con los pies en el ancla y el cuerpo hecho un ovillo, y así lo vimos volar lejos, arrastrado por el viento, frenando apenas la carrera del globo, y desaparecer hacia el mar (...) se supuso que el viejo moribundo había desaparecido mientras volaba en medio del golfo (Calvino, 2002, 261-262),

Por supuesto, toda victoria frente a la entropía es temporal, provisional, prestada. Todo se muere; los árboles son talados, el barón deja de existir, los relatos se acaban. Así termina El Barón Rampante, uniendo la vida de los árboles, la del protagonista, y la de la escritura misma:

El cielo está vacío, y a nosotros, los viejos de Ombrosa, habituados a vivir bajo aquellas verdes cúpulas, nos daña los ojos mirarlo. Se diría que los árboles no han aguantado, después de que mi hermano se fue, o que a los hombres les ha entrado la furia del segur (...).

Ombrosa ya no existe Al mirar al cielo despejado, me pregunto si ha existido alguna vez. Aquella abundancia de ramas y hojas, bifurcaciones, lóbulos, penachos, diminuta y sin fin, y el cielo sólo en retazos irregulares y diseminados, quizás sólo existieron para que pasase mi hermano con su ligero paso de chamarón, era un bordado hecho sobre la nada que asemeja a este hilo de tinta que he dejado correr por páginas y páginas, atiborrado de tachaduras, de remisiones, de chafarrinones nerviosos, de manchas, de lagunas, que a veces se desgrana en gruesos granos claros, a veces se espesa en signos minúsculos como semillas puntiformes, ora se retuerce sobre sí mismo, ora se bifurca, ora enlaza grumos de frases con contornos de hojas o nubes, y luego se atasca, y luego vuelve a enroscarse, y corre y corre y se devana y envuelve en un último racimo insensato de palabras, ideas, sueños y se acabó. (Calvino, 2002, 262-263). 


\section{Biología y Literatura}

¿Cómo surge la vida? Hoy en día se sabe que la evolución no se dio por cambios continuos y graduales sino en períodos de grandes cambios alternados con periodos de estabilidad, en lo que se conoce como equilibrio puntuado; este patrón de cambio contradice al darwinismo clásico, que predeciría una rata de cambio uniforme debido a mutaciones aleatorias que se reproducen en entornos favorables (Capra, 1996, 219-220). Para dar cuenta de este patrón de cambio, es necesario acudir a la idea de emergencia (que se comienza a utilizar cada vez más en diversos campos de la ciencia, ver Morowitz, 2002); a la idea del orden que surge en un nivel de observación de la interacción de factores en un nivel inferior (p.ej, los patrones de organización en un nido de hormigas no se encuentran en las hormigas individuales, sino que emergen de la manera en que se relacionan). Es necesario completar la teoría de la evolución con elementos como la co-evolución: el acoplamiento entre la evolución de los organismos y la de su entorno es tan estrecho que debe considerarse un único proceso evolutivo; en especial, comprender la evolución pasa por comprender la simbiosis, especialmente al nivel de las bacterias (Capra, 1996, 222 y ss). Una visión enriquecida de la evolución desplaza nuestra mirada de un sistema comprensible mecánicamente, en el que la aleatoriedad es la única fuente de la creatividad, a una "danza en desenvolvimiento que opera a través de sutiles relaciones entre la competencia, la cooperación, la creación y la adaptación mutua” (Capra, 1996, 222).

Como en El Barón Rampante cuando Cosimo está por caer, el peligro de supervivencia, de que un proceso no pueda seguir reproduciéndose, resulta ser una fuente de creatividad. En la joven Tierra, tras el desarrollo de la fotosíntesis, se produjo una escasez de hidrógeno para la producción de carbohidratos. A la sazón, no existían bacterias capaces de extraer el hidrógeno del agua. Fueron las algas verdeazuladas las que, creando un nuevo tipo de fotosíntesis, pudieron quebrar las moléculas de $\mathrm{H} 2 \mathrm{O}$, utilizando el hidrógeno y excretando el oxígeno. Para el ecosistema entonces en existencia, el oxígeno resultaba altamente tóxico, y se produjo la extinción de varias especies debido a la acumulación de oxígeno en la atmósfera. Pero donde está el peligro crece también lo que salva: el entorno se hizo propicio para una nueva y espectacular innovación: el uso del oxígeno como combustible en la respiración, el origen remoto de los animales (Capra, 1996, 234 y ss). La misma abundancia de un elemento tóxico produce las condiciones para la emergencia de células que lo utilizan como fuente de energía: el jinete del cubo asciende porque su cubo está vacío.

¿Qué es la vida? Los seres vivos, según Maturana y Varela, son sistemas autopoiéticos, cerrados con respecto a su organización y abiertos respecto a la energía y la materia (1994). El término “autopoiético” (que refiere etimológicamente a la misma raíz que "poesía”) quiere decir que son sistemas que se producen a sí mismos. Son cerrados organizacionalmente porque los componentes de una red autopoiética se producen unos a otros; y abiertos respecto a la materia y a la energía porque, para que un ser vivo 
se produzca a sí mismo debe interactuar con el entorno que le rodea mediante diversos procesos (p.ej, alimentación, respiración, excreción). Nosotros, por ejemplo, estamos abiertos al entorno circundante; comemos y respiramos y así nos regeneramos continuamente; esta apertura, no obstante, está referida a un patrón, a una organización, que proviene de nosotros mismos, no del entorno circundante. (Capra, 1996, 157 y ss). Dicho de otro modo, los seres vivos son cadenas causales que permanecen en el tiempo. ¿Cómo es posible? El efecto de esta cadena causal es la cadena causal misma: la serpiente se come su propia cola, el relato vive del relato.

Nuestro perseverar en nuestro ser no depende de que estemos hechos siempre de la misma materia (si cesa el flujo de materia, somos momias embalsamadas, como Lenin en su mausoleo), sino de la perseverancia de un mismo proceso. Dicho de otro modo, nos parecemos más a los torbellinos que a las mesas de madera; continuamos porque continua un determinado proceso causal que conserva una organización característica. I. Prigogine describe a torbellinos y a seres vivos como estructuras disipativas. Un ejemplo simple de estructura disipativa es el torbellino, cerca al sifón cuando lo abrimos y dejamos correr el agua de la tina. El agua fluye a través del torbellino sin ser nunca la misma agua, y no obstante el torbellino conserva una organización bien definida. Esta organización depende de procesos causales complejos que dependen de la gravedad, la fuerza centrífuga y de ciertos factores que quiebran el flujo uniforme de agua hacia el sifón haciendo que entre más desde un lado que desde otro, lo que eventualmente genera el movimiento rotatorio. (Capra, 1996, 164-165).

Las estructuras disipativas producen orden a partir del desorden, son sistemas alejados del equilibrio termodinámico. Es decir, quedan por fuera, de manera local y temporal, de la segunda ley de la termodinámica, según la cual el universo, por la disipación de calor, tiende hacia un estado de máximo desorden (Capra, 1996, 47-49). Del mismo modo, un pájaro viola, de manera local y temporal, la ley de la gravedad, y El Barón Rampante viola, de manera local y temporal, todas las restricciones causales que impiden que un aristócrata del XVIII viva plenamente sin jamás bajarse de los árboles.

La obstinación del Barón Rampante, su elegir ciertas reglas a las cuales atenerse, es análoga al hecho de que es la misma actividad de un sistema autopoiético la que define la identidad del sistema mismo y por lo tanto los criterios según los cuales el sistema en cuestión permanece o no en el tiempo: “(...) todos los cambios que él experimente sin perder su identidad y, por lo tanto, manteniendo sus relaciones definitorias son necesariamente determinados por su organización homeostática” (Maturana \& Varela, 1994, 90). El asunto es notable: una actividad se impone a sí misma reglas para obrar y resulta que depende del cumplimiento o no de estas reglas el que la actividad persista como tal: a la analogía que establecemos entre vida y literatura habría que añadir un tercer término: el juego (ver Huizinga, 1972). Podemos separar el carácter obstinado de lo vivo y lo creativo en dos momentos: un caprichoso fijarse una regla de operación, y 
un tenaz esfuerzo por seguirla. En este punto resulta indispensable citar extensamente el cuento Cantata a Satanás de Oscar de la Borbolla:

Abraham amaba a Sara cada mañana clara: pasaba la manaza, arañaba la lana, arrancaba la bata, la abrazaba; clavaba las garras hasta matarla.

Sara atarantada, callaba harta. Abraham la cansaba. "Ya nada habrá," (mascaba.) Tras la sábana, ama a la mala; ataca, aplasta, brama.

Abraham acababa, apartaba la cara, jamás apagaba la flama a Sara, gran dama avasallada; daba palmadas a la santa, la llamaba "alma"; mas jamás la agradaba.

Fracasaba la casa blanca, la sagrada paz.

Sara maltrataba a Abraham: "¿Habrá raza más mala para la cama?", ladraba.

Abraham agarraba la garganta a la casta casada, la arrastraba a la sala. Sara sacaba las palabras más bravas, las dagas pasmaban la faz al papanatas.

(...)

Mas avanzada la mañana, para hallar más armas, arrasaban la casa, a la par lanzaban lámparas, tazas, navajas hasta sangrar. Para acabar la tanda, las almas atacaban. Las bravatas, tragaban carcajadas amargas, ataban máscaras aplacadas a la cara.

"¡Andá haragán, a trabajar para ganar la plata!", cantaba avara Sara, amarrada a la más vana maldad: mandar para calmar la falta, agachar al canalla, calar más.

Abraham, fantasmal facha, agarra la pala, zafa la aldaba, baja a la calzada, pasa la barranca hasta hallar la cabaña.

Allá pagaban tan mal.

(...)

Sara ajada, más flaca cada mañana, lavaba la casa: arrancaba a las sábanas manchas, canas, caspa; al alzar la sala hallaba cáscaras, naranjas, tazas rajadas, latas achatadas. Asaba papas, adaptaba las aspas para machacar calabazas, aplanaba la masa, la salaba. Al planchar las maltratadas faldas aplastaba arañas, raspaba las manchadas bragas.

(...)

Jamás manaban al trabajar gratas palabras.

Cansada, harta, la gran dama nada amaba. Masacrar a las ratas. Matar a Abraham tramaba. Más apagada, blanda, lanzada al drama, nada hallaba para marchar a la paz, acabar la maraña, traspasar tanta trastada, dar mañas al plan.

Sara bajaba a la plaza, andaba al altar, llamaba para aval a Satanás, trazaba rara cábala. Las campanas acallaban las palabras; mas daban alas para pactar.

(...)

A tanta llamada, Satanás da la cara; alarga la gran carta.

Sara la agarra; la halla banal, payasa, larga; mas labra la palabra "Sara" para agradar a Satanás. La Gran Cabra atrapa la carta, la lacra; saca la caja, alza la tapa, saltan salamandras, da a Sara la bala para 
sanar: "Marcha a la carpa --manda--, allá hallaras blanda paja, gran galán para la carnal falta."

(...)

Sara halla a Baltasar. Charlan: "Ah... ¿ Satanás manda?" "Ajá".

Pasan a la cámara, atrancan la chapa, tragan pasas, alzan la garrafa, danzan.

Baltazar saca a Sara la capa, la falda, las mallas. Apagan la lámpara, aplastan la manta, acatan la carta: gran cascada, gran catarata. Alta parvada, sacras arpas.

(...)

Baltasar halaga a Sara, da alhajas, ámbar, ágatas; la abraza, la llama "hada"; saca la palangana, la baña. Baltasar la ama.

(...)

Acabada la hazaña, Sara apalabra a Baltasar. Van a la casa blanca (...) Baltasar carga la canasta a Sara. Alcanzan la calzada, pasan la casa. Hallan a Abraham hasta atrás, mala cara, faz atada.

"Ah, malvada --brama--, chacal para bacanal." Abraham alza la pala. Sara salta para atrás. Baltasar avanza: "!Calma ganan!"

Abraham saca larga daga. Satanás atrasa a Baltasar, da armas.

Salta la bala. Mata a Abraham. Las babas atascan las palabras.

Abraham va al mas allá.

Sara calma a Baltasar. Cavan gran zanja a la sala para lanzar al carcamal.

Sara alaba la talla a Baltasar. Van a la cama, jalan la manta.

La mañana aclara las gargantas, cantan, danzan.

Baltasar abraza a Sara: "Amada hada," la llama. (2001)

Superficialmente, la gracia del relato está en la regla a la que se ciñe, y su virtud sería tan sólo la habilidad de encontrar las palabras adecuadas. Una mirada más detenida revela, sin embargo, que, sobre el telón de fondo de la regla autoimpuesta, se produce un mundo de sentido, en el que se encuentra la verdadera virtud del relato. El mundo que presenta es pesado, tedioso, aporético; es un mundo en el que sólo Satanás puede dar una salida. Es en el cruce entre la regla de juego y el mundo de sentido que cobran poder oraciones como “Allá pagaban tan mal”, o “Jamás manaban al trabajar gratas palabras”.

La autopoiesis también crea espacios en los que emerge el sentido, como mostraremos. En la teoría de la autopoiesis cognición y esfuerzo por la vida son una sola cosa: las modificaciones que lleva a cabo la estructura autopoiética para adaptarse a un entorno cambiante. Ahora bien, a qué perturbaciones del entorno responde un sistema autopoiético es algo que está especificado por el sistema mismo (Capra, 1996, 259 y ss); el ser vivo sólo responde a cierto tipo de cambios en su entorno, mientras que otros ni siquiera existen en su mundo. Las anguilas perciben campos eléctricos; ciertos organismos microscópicos perciben la acidez del agua en que se encuentran; los perros tienen un enorme poder olfativo pero no perciben colores: en cada caso, el organismo percibe aquello que es pertinente para su vida. El mundo que percibe y frente al que reacciona el organismo es un 
producto de los órganos de percepción y acción del organismo mismo: así, Jakob von Uexküll puede crear un nuevo tipo de biología, que se pregunta por la naturaleza del mundo vivencial de las diferentes especies (p.ej, 1945): una misma pradera es algo radicalmente diferente para una abeja, un venado, un perro, y un ser humano; en cada caso hay un mundo vivencial, un Umwelt, diferente. Lo que importa y lo que no, lo que es relevante y lo que no, depende del Umwelt en cuestión: una cruz de madera en una iglesia puede tener sentidos diferentes para el cura, los pichones que hicieron su nido en un vértice y las termitas que han encontrado una fuente de alimento. El sentido del objeto está dado, en cada caso, por la actividad autopoiética.

Lo pesado del reino de lo humano, de lo cotidiano, de lo ya sabido y ya mirado, por un lado; lo pesado de las leyes físicas y químicas que condenan al universo a un estado de equilibrio térmico y químico, inmóvil y máximamente entrópico, por otro. Literatura y vida son ambas empresas negentrópicas, autopoiéticas y creadoras de sentido. Desencadenan procesos que se producen a sí mismos y se complejizan y diversifican (por la evolución, en el caso de la vida, por la dinámica interna del relato, en el caso de la literatura; y en ambos casos gracias a una tensión creativa); empresas, en ambos casos, necesitadas de una dinámica, de un proceso, que produzca orden frente a las fuerzas del desorden. En este punto, resulta notable la similitud entre vida biológica y literatura, como si una misma creatividad impulsara a una y otra. Los valores literarios que propone Calvino (levedad, rapidez, consistencia) se nos aparecen como valores sin más. Nos sentimos convocados a la defensa de lo creativo, de lo vivo (de lo que lucha contra la pesadez y la inercia) como algo valioso en sí mismo, y aún como fuente de valores. 


\section{Bibliografía}

Calvino, I. (1989), Seis Propuestas para el Próximo Milenio. Siruela, Madrid.

Ídem (2002), El Barón Rampante. Planeta/ El Nacional, Caracas.

Capra, F. (1996), The Web of Life. Harper Collins. Londres.

De la Borbolla, O. (2001), Cantata a Satanás, tomado de http:// rubensada.blogspot.com/2008/07/cantata-satans-scar-de-la-borbolla.html, recuperado el 26 de mayo de 2013

Huizinga, J. (1972), Homo Ludens. Alianza, Madrid.

Kafka, F. (1999), La Muralla China y Otros Relatos. Alianza, Madrid.

Maturana, H. \& Varela, F. (1994), De Máquinas y Seres Vivos. Editorial Universitaria, Santiago de Chile.

Melville, H. (1979). Bartleby, el escribiente. Bruguera, Madrid.

Morowitz, H.J (2002). The Emergence of Everything. Oxford, Nueva York.

Serres, M. (2004). El Contrato Natural. Pre-textos, Valencia.

Spinoza, B. (1999). Ética. Alianza, Madrid.

Rodríguez Romero, N. (2007). Elementos para una teoría del microcuento. UPTC, Tunja.

V. Uexküll, J. (1945). Cartas biológicas a una dama. Revista de Occidente, Madrid.

Recibido: 14.01.2012

Aceptado: 16.10.2013 